\title{
Comparison of Facts Controller for Power Quality Problems in Power System
}

\author{
Budi Srinivasarao $^{1 *}$, G. Sreenivasan ${ }^{2}$ and Swathi Sharma ${ }^{1}$ \\ 'Department of EEE, Jodhpur National University, Jodhpur, Rajasthan - 342003, India; bsreee2013@gmail.com, \\ er.swati.sharma15@gmail.com \\ ${ }^{2}$ Department of EEE, Intel Engineering College, Anathapur, Andhra Pradesh - 515004, India; \\ gsn.anusree@gmail.com
}

\begin{abstract}
The advancement in the technology, in the last decade has seen drastically increase in the electrical loads and multiplying in numbers of complexity of the devices that has low quality of distribution. A Power quality problem is an occurrence manifested as a nonstandard voltage, current or frequency that results in a failure or misoperation of end user equipment. This paper presents general problems of power quality such as sags and swells. In this paper, we observed the performance and also compared the operation and mitigation process of power quality problems by using UPQC and DPFC. The performance of these systems is observed in Matlab/Simulink.
\end{abstract}

Keywords: Distributed Power Flow Controllers, FACTS Controllers, Power Quality

\section{Introduction}

With increasing applications of loads and electronically switched devices in distribution systems and industries, power quality problems, such as variation of voltages and faults and distortions ${ }^{1}$. Generally, power quality problems is meant by wide range of disturbances occur in voltage and current and called as sag/swell conditions and occurs a magnitude change from 0.1 to 0.5 with a short span of time.

In order to meet PQ standard limits ${ }^{2}$, it might be important to incorporate some kind of remuneration. Advanced arrangements can be found as active correction or active filtering. A shunt active power filter is suitable for the concealment of negative burden impact on the supply organize, however in the event that there are supply voltage blemishes, a series active power filter may be required to provide full compensation ${ }^{3,4}$.

Generally, there are a wide range of systems to relieve voltage sags and swells, however the utilization of a custom power gadget to be the most effective strategies. Exchanging off a vast inductive load or energizing a substantial capacitor bank is an average framework occasion that causes swells ${ }^{5}$. This paper introduces a new method such as DPFC and this result is compared with another custom power device such as UPQC.

\subsection{Configuration of UPQC}

A brought together Power-Quality Conditioner (UPQC) is the augmentation of the bound together power-stream controller (UPFC) idea at the circulation level is one the best answer for make the general power dispersion framework more soundly. It comprises of consolidated arrangement and shunt converters for synchronous pay of voltage and current flaws in a supply feeder. The configuration of UPQC is shown in Figure $1^{6}$.

\subsection{Configuration of DPFC}

The configuration of DPFC system contains elimination of DC-link capacitor and using $3^{\text {rd }}$ harmonic current to active power exchange.

The DPFC consists of shunt and a associated series converters. The shunt converter is only same as STATCOM, while the arrangement converters utilize the D-FACTS idea. Every converter inside of the DPFC is autonomous

${ }^{*}$ Author for correspondence 
and has a different DC join capacitor to give the obliged DC voltage. Figure 2 demonstrates the structure of DPFC that is utilized as a part of a change framework with two parallel lines ${ }^{7}$. The control capacity of the UPFC is given by the consecutive association between the shunt and the arrangement converters with DC join, which permits the dynamic power to trade unreservedly. To guarantee that the DPFC has the same control capacity as the UPFC gadget, a technique that permits the trading of dynamic power between converters without DC connection is the essential. In the $\mathrm{DPFC}^{8}$, there is a typical association between the AC terminals of the shunt and the arrangement converters, which is the transmission line. In this way, it is permits to trade the dynamic power through the AC terminals of the converters.

\subsection{Control Circuit for DPFC}

As per the control diagram of DPFC which is shown in Figure 3 it is clear that the DPFC is as it divided into: 1. Central controller, 2. Series controller and 3. Shunt controller?.

\subsection{Merits of DPFC}

The DPFC has the following advantages in comparison with UPQC, such as:

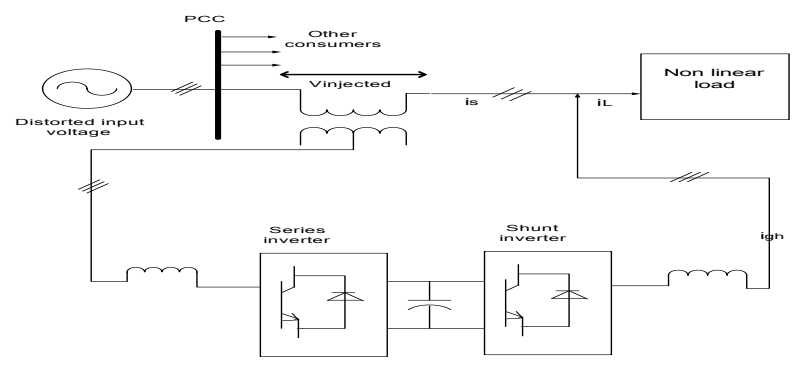

Figure 1. Configuration of UPQC.

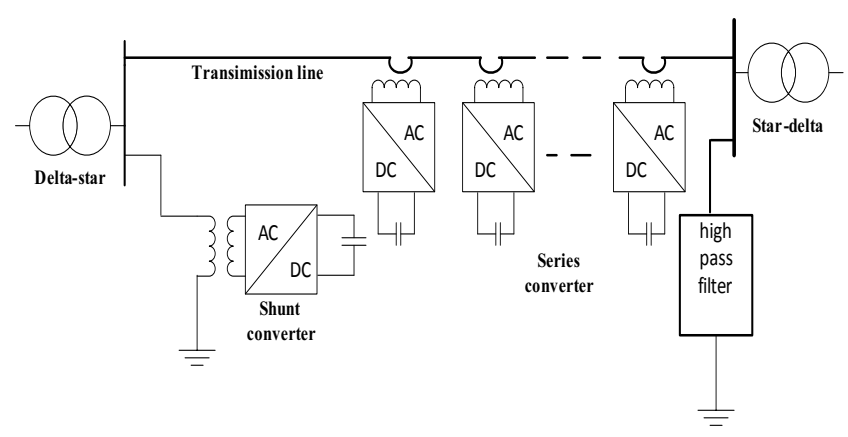

Figure 2. Basic configuration of DPFC.

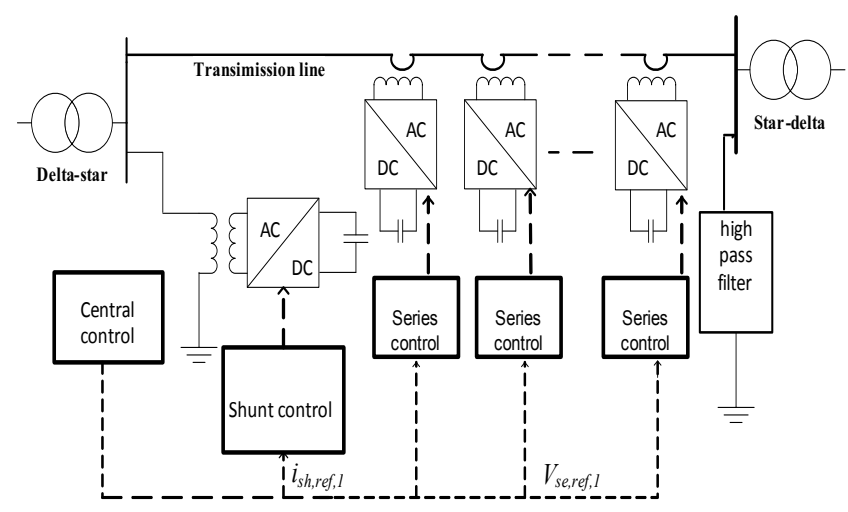

Figure 3. Closed loop control diagram of DPFC.

- High control capacity.

The DPFC can control all parameters of transmission system

- High unwavering quality.

The arrangement converters repetition builds the DPFC dependability amid converters operation. That is to say, if one of arrangement converters falls flat, the others can keep on working.

- Low cost.

The single-stage converters rating, in examination with three-stage converters are low. Besides, the arrangement converters, in this design, no compelling reason to any voltage disengagement to unite in line. We can utilize the single turn transformers for arrangement converters hanging ${ }^{10}$.

\section{Simulation Diagram and Results}

The mitigation methods for sag/swell condition is implemented in a single machine system are analyzed and observed the results. The simulation diagram is constructed for both UPQC and DPFC by considering the following basic diagram as shown in Figure 1 and Figure 2 respectively.

Figure 4 shows the simulation result of three phase output voltage. In this system the fault occurs from 0.05 sec to $0.15 \mathrm{sec}$. During this period there is sag occurs in load voltage with difference magnitude of $0.8 \%$. During this period of fault the load current raises its magnitude around 1.2\% per unit as shown in Figure 6. The voltage sag and current swell obtained by fault condition between times $0.5 \mathrm{sec}$ to $1.5 \mathrm{sec}$ is compensated using Distributed 


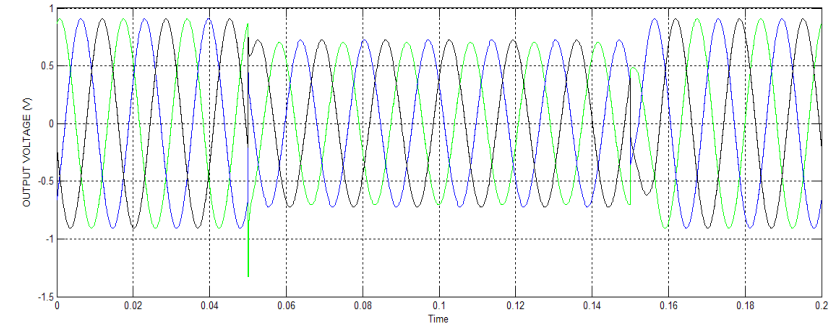

Figure 4. Simulation results for voltage sag condition.

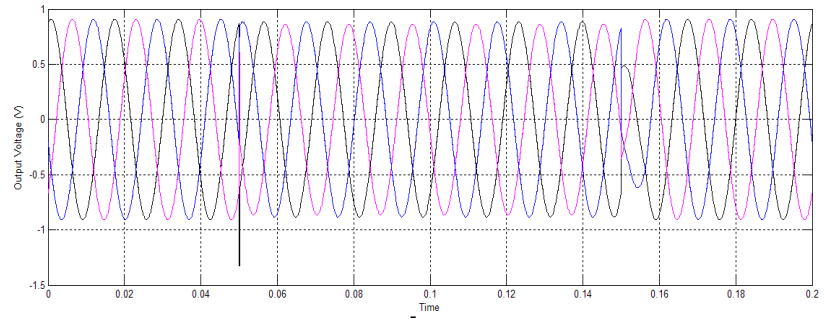

Figure 5. Simulation results for mitigation of Voltage sag.

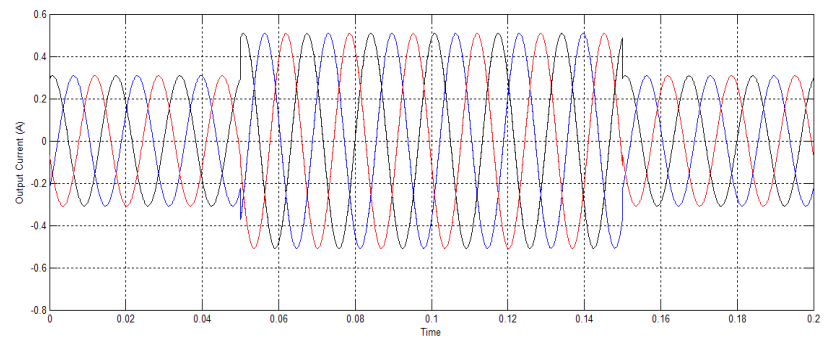

Figure 6. Simulation results for current swell condition.

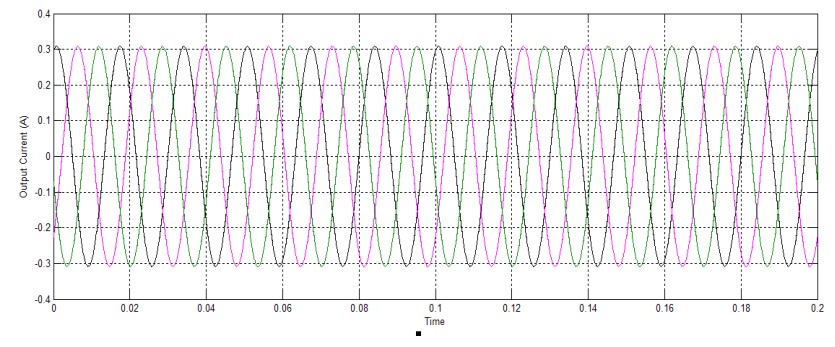

Figure 7. Simulation results for mitigation of current swell.

Power Flow Controller. The compensated voltage and current waveforms for the system is as shown in Figure 5 and Figure 7.

This paper also includes comparison of THD values in case of UPQC and DPFC techniques. The THD value obtained in case of UPQC is $12.36 \%$ and the THD value obtained in case of DPFC is $3.88 \%$ as shown in Figure 8 and Figure 9.

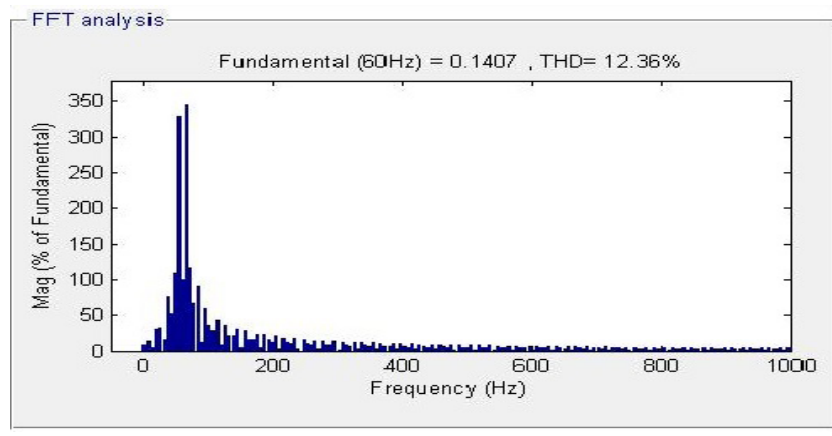

Figure 8. THD value of system output voltage with UPQC.

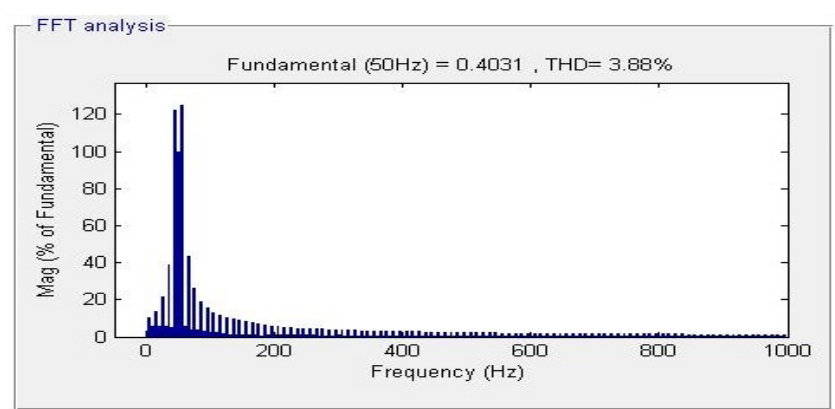

Figure 9. THD value of DPFC (pi controller) load voltage.

\section{Conclusion}

In this paper a new concept of controlling power quality problems by DPFC controller. The simulation results for sag and swell mitigations are observed in case of both DPFC and UPQC. Out of these two methods the DPFC has good THD value as compared with UPQC. Therefore, the obtained simulation results by DPFC show the effectiveness of power quality enhancement as compared with all other FACTS devices.

\section{References}

1. Faiz J, Shahgholian GH, Torabian M. Design and simulation of UPFC for enhancement of power quality in transmission lines. IEEE International Conference on Power System Technology. 2010; 24(4).

2. Gouthamkumar N, Sharma V, Naresh R. Disruption based gravitational search algorithm for short term hydrothermal scheduling. Expert Systems with Applications. 2015; 42:7000-11.

3. Patne INR, Thakre KL. Factor affecting characteristics of voltage sag due to fault in the power system. Serbian Journal of Electrical Engineering. 2008; 5(1). 
4. Enslin JR. Unified approach to power quality mitigation. Proc IEEE International Symposium on Industrial Electronics (ISIE '98). 1998; 1.

5. Singh B, Al-Haddad K, Chandra A. A review of active filters for power quality improvement. IEEE Trans Industrial Electronics. 1999; 46(5):960-71.

6. Hannan MA, Mohamed A. PSCAD/EMTDC simulation of unified series-shunt compensator for power quality improvement. IEEE Transactions on Power Delivery. 2005; 20(2).

7. Olimpo AL, Acha E. Modeling and analysis of custom power systems by PSCAD/EMTDC. IEEE Transactions on Power Delivery. 2002; 17(1):266-72.
8. Pohjanheimo P, Lakervi E. Steady state modeling of custom power components in power distribution networks. Proc IEEE Power Engineering Society Winter Meeting. 2000 Jan; 4:2949-54.

9. Yuan ZH, de Haan SWH, Frreira B, Cevoric D. A Facts device: Distributed Power Flow Controller (DPFC). IEEE Transaction on Power Electron. 2010 Oct; 25(10).

10. Yuan ZH, de Haan SWH, Frreira B. DPFC control during shunt converter failure. IEEE Transaction on Power Electron. 2009. 